DOSSIÊ TEMÁTICO: Formação inicial de professores em contextos escolares e binômio teoria/prática nos estágios supervisionados

do/ https://doi.org/10.22481/rpe.v16i43.6774

\title{
ESTÁGIO SUPERVISIONADO NO CURSO DE PEDAGOGIA: O QUE DIZEM OS PROJETOS PEDAGÓGICOS E QUAIS SENTIDOS PRODUZIDOS POR EGRESSOS $^{1}$
}

SUPERVISED INTERNSHIP IN THE PEDAGOGY COURSE: WHAT THE PEDAGOGICAL PROJECTS SAY AND WHAT SENSES PRODUCED BY GRADUATES

\author{
PRÁCTICA SUPERVISADA EN EL CURSO DE PEDAGOGÍA: LO QUE DICEN LOS \\ PROYECTOS PEDAGÓGICOS Y LOS SENTIDOS PRODUCIDOS POR LOS \\ GRADUADOS
}

\author{
Liliana Soares Ferreira \\ Universidade Federal de Santa Maria - Brasil \\ Luiza da Silva Braido \\ Universidade Federal de Santa Maria - Brasil \\ Mariglei Severo Maraschin \\ Universidade Federal de Santa Maria - Brasil \\ Dulcineia Libraga Papalia de Toni \\ Universidade Federal de Santa Maria - Brasil
}

\begin{abstract}
Resumo: Apresenta-se análise dos Projetos Pedagógicos (PP) dos cursos de Pedagogia das cinco Universidades Federais do Rio Grande do Sul, objetivando evidenciar os sentidos em encaminhamentos em relação aos Estágios Supervisionados. Partiu-se do suposto que o estágio supervisionado seria o tempo e o espaço privilegiados para o contato, o trabalho e a inserção no campo profissional, mediante projeto e orientação por parte dos professores do Curso. Quanto aos aspectos teóricos e metodológicos, foram realizadas duas etapas. Na primeira, aconteceu análise documental dos Projetos Pedagógicos dos cinco cursos de Pedagogia. Na segunda etapa foi enviado um questionário para um grupo de egressos do curso de Pedagogia de uma das cinco universidades, composto por questões objetivando contemplar e relacionar à análise realizada nos PPs. As questões versavam sobre a concepção, vivência/experiência e a avaliação do Estágio Supervisionado no Curso de Pedagogia naquela universidade. Onze

1 [1] Texto produzido a partir de projeto desenvolvido com financiamento do Conselho Nacional de Desenvolvimento Científico e Tecnológico - CNPq (Processo 303650/2016-8) e da Fundação de Apoio à Pesquisa no Estado do Rio Grande do Sul - FAPERGS (Processo 2333-2551/14-7) e Coordenação de Aperfeiçoamento de Pessoal de Nível Superior -Brasil (CAPES).
\end{abstract}


interlocutores, dez mulheres e um homem, egressos do Curso entre 2013 e 2020, participaram das entrevistas. Os dados foram analisados pela Análise de Movimentos de Sentidos, técnica elaborada pelo grupo de pesquisa no qual se trabalha. Uma das percepções, após o estudo, é haver estágio supervisionado previsto nos projetos pedagógicos. Entretanto, não foram encontrados expressos sentidos e concepções de estágio supervisionado. Do mesmo modo, os discursos dos egressos descrevem como prática, não raramente, dissociando-a da teoria e considerando-a prioridade não vislumbrada no Curso.

Palavras chave: Pedagogia; Teoria e prática; Estágio Supervisionado; trabalho pedagógico.

Abstract: An analysis of the Pedagogical Projects (PP) of the Pedagogy courses at the five Federal Universities of Rio Grande do Sul is presented, aiming to highlight the meanings in referrals in relation to the Supervised Internships. It was assumed that the supervised internship would be the privileged time and space for contact, work and insertion in the professional field, through project and guidance by the teachers of the Course. As for the theoretical and methodological aspects, two stages were carried out. In the first, there was a documentary analysis of the Pedagogical Projects of the five Pedagogy courses. In the second stage, a questionnaire was sent to a group of graduates of the Pedagogy course at one of the five universities, composed of questions aimed at contemplating and relating to the analysis carried out in the PPs. The questions were about the conception, experience / experience and the evaluation of the Supervised Internship in the Pedagogy Course at that university. Eleven interlocutors, ten women and one man, graduating from the Course between 2013 and 2020, participated in the interviews. The data were analyzed by the Analysis of Movement of Senses, a technique developed by the research group in which we work. One of the perceptions, after the study, is that there is a supervised internship foreseen in the pedagogical projects. However, no supervised internship meanings and conceptions were found. Likewise, the speeches of the alumni describe it as a practice, not infrequently, dissociating it from the theory and considering it a priority not seen in the Course.

Keywords: Theory and practice; Supervised internship; pedagogical work.

Resumen: Se presenta un análisis de los Proyectos pedagógicos (PP) de los cursos de pedagogía en las cinco universidades federales de Rio Grande do Sul, con el objetivo de resaltar los significados en las referencias en relación con las pasantías supervisadas. Se asumió que la pasantía supervisada sería el tiempo y el espacio privilegiado para el contacto, el trabajo y la inserción en el campo profesional, a través del proyecto y la orientación de los maestros del Curso. En cuanto a los aspectos teóricos y metodológicos, se llevaron a cabo dos etapas. En el primero, se realizó un análisis documental de los Proyectos pedagógicos de los cinco cursos de pedagogía. En la segunda etapa, se envió un cuestionario a un grupo de graduados del curso de Pedagogía en una de las cinco universidades, compuesto de preguntas destinadas a contemplar y relacionarse con el análisis realizado en los PP. Las preguntas fueron sobre la concepción, experiencia / experiencia y la evaluación de la pasantía supervisada en el curso de pedagogía en esa universidad. Once interlocutores, diez mujeres y un hombre, graduados del Curso entre 2013 y 2020, participaron en las entrevistas. Los datos fueron analizados por el Análisis del Movimiento de los Sentidos, una técnica desarrollada por el grupo de investigación en el que trabajamos. Una de las percepciones, después del estudio, es que hay una pasantía supervisada prevista en los proyectos pedagógicos. Sin embargo, no se encontraron significados y conceptos de pasantías supervisadas. Del mismo modo, los discursos de los alumnos lo describen como una práctica, no con poca frecuencia, disociándolo de la teoría y considerándolo una prioridad que no se ve en el Curso.

Palabras clave: Pedagogía; Teoría y práctica; Práctica Supervisada; trabajo pedagógico. 


\section{Aspectos iniciais}

O presente texto apresenta uma análise sobre os Projetos Pedagógicos (PP) dos cursos de Pedagogia das cinco Universidades Federais do Rio Grande do Sul: Universidade Federal do Rio grande do Sul (UFRGS), Universidade Federal de Pelotas (UFPEL), Universidade Federal de Santa Maria (UFSM), Universidade Federal de Rio Grande (FURG) Universidade Federal do Pampa (UNIPAMPA). A análise dos PPs teve como objetivo principal evidenciar os sentidos produzidos em relação aos Estágios Supervisionados.

Essa análise pautou-se pela questão: qual o sentido do estágio supervisionado nos projetos pedagógicos do Curso de Pedagogia e como são encaminhadas estas atividades curriculares obrigatórias? Partiu-se do suposto que, se os egressos do Curso de Pedagogia trabalharão em aula ou em outras atividades pedagógicas, o estágio supervisionado seria o tempo e o espaço privilegiados para o contato, o trabalho e a inserção no campo profissional, mediante projeto e orientação por parte dos professores do Curso.

O texto, então, é um estudo, de caráter bibliográfico e mediante análise documental e entrevistas. Quanto a esses aspectos teóricos e metodológicos, foram realizadas duas etapas. $\mathrm{Na}$ primeira, trabalhou-se para o alcance dos objetivos específicos, realizando análise documental dos Projetos Pedagógicos dos cinco cursos de Pedagogia, visando a: a) analisar a concepção de estágio; b) analisar a questão da teoria, da prática e práxis nos mesmos; c) quanto à organização, observar como os estágios estavam distribuídos na matriz curricular e em que momento os futuros pedagogos(as) adentravam a escola; d) observar a relação dos PPs com as Diretrizes Curriculares Nacionais (DCNs, Resolução CNE/CP 1/2006), bem como as Diretrizes para a formação dos professores (2018).

Na segunda etapa foi escolhida uma Universidade Federal[1], no caso a UFSM, por sua proximidade com as autoras. Em continuidade, foi enviado um questionário para um grupo de egressos do curso de Pedagogia, composto por questões objetivando contemplar e relacionar à análise realizada nos PPs. As questões versavam sobre a concepção, vivência/experiência e a avaliação do Estágio Supervisionado no Curso de Pedagogia naquela universidade. O objetivo da segunda etapa foi perceber se os sentidos produzidos pelos entrevistados sobre os Estágios Supervisionados estavam em consonância com os sentidos evidenciados nos PPs e nos Currículos do curso. Nessa fase, houve o convite à participação na entrevista a egressos do Curso de Pedagogia, por e-mail, e aceitaram onze interlocutores, dez mulheres e um homem, concluintes do Curso, na UFSM, entre 2013 e 2020. 
Os dados foram analisados pela Análise de Movimentos de Sentidos, técnica elaborada pelo grupo de pesquisa no qual se trabalha. Trata-se de leitura, análise dos sentidos em seus movimentos e sistematização. Essas três etapas acontecem ora separadas, ora concomitantemente, de modo que os pesquisadores vão adentrando nos (con)textos dos dados e, na medida em que analisam, interpretam, produzem argumentos que indicam a interpretação e compreensão dos sentidos, visando a responder às problematizações que deram origem ao estudo.

Uma vez sistematizada a análise, passou-se à elaboração dos argumentos apresentados nesse texto. Parte-se de breve exposição sobre os estágios nos cursos de Pedagogia, para visualizá-los, na seção seguinte, dentro dos projetos pedagógicos dos cursos das universidades públicas federais do Estado do Rio Grande do Sul e nos discursos dos egressos de um desses cursos. A seguir, apresentam-se considerações finais, cujo objetivo é finalizar a discussão até o momento e, ao mesmo tempo, possibilitar que continue o debate.

\section{O curso de Pedagogia no RS e os estágios supervisionados}

O Curso de Pedagogia pioneiro no Brasil é da década de 1930. Portanto, de 1835 a 1839, os professores estudavam para a profissão nos Cursos Normais. O Curso de Pedagogia nasce com essa herança, a de dar continuidade ao Curso Normal, ou seja, garantir, no âmbito do Ensino Superior, a profissionalização dos professores. A promulgação do Decreto-Lei 1.190 de 04 de abril de 1939, reorganizando a estrutura da Faculdade Nacional de Filosofia, também dá origem às seções de Filosofia, Ciências, Letras e Pedagogia, amparadas por uma subseção, a de Didática (SAVIANI, 2008). O Curso de Pedagogia, nesse contexto, formaria bacharéis e técnicos educacionais, para, se quisessem, após, realizar um ano de aulas de Didática, também se constituírem professores. Observa-se nessa reestruturação dois aspectos que, até hoje, demarcam o lugar social da Pedagogia: o primeiro, diz respeito à cisão tradicional com a Filosofia. Esta já era uma área do conhecimento consagrada e, enquanto abrigou a Pedagogia, garantiu-lhe esse lugar ligado, no imaginário, ao aprofundamento e à reflexão; o segundo é a cisão entre Pedagogia e Didática, quando, se sabe esta é uma subárea daquela. Esses dois aspectos estão ligados à concepção de estágio no curso de Pedagogia: “[...] supondo que o perfil profissional do pedagogo já estaria definido, concebeu um currículo que formaria o bacharel em pedagogia entendido como o técnico em educação que, ao cursar didática geral e especial, se licenciaria como professor" (SAVIANI, 2008, p. 41). 
O primeiro curso de Pedagogia no Estado gaúcho foi criado na Universidade Federal de Rio Grande do Sul, em 1942. Naquela época, o Curso, em acordo com o processo de desenvolvimento industrial do país, sofria as influências de duas tendências pedagógicas: de um lado a Escola Nova, propondo uma mudança na abordagem educacional, na medida em que o estudante deveria ser o centro do processo pedagógico; de outro, resistindo e fortificando-se, a Pedagogia Tradicional, enraizada no país, tendo por suposto que os professores são o centro do pedagógico, têm o conhecimento e "ensinam" ou "transmitem" para o estudante, que nada sabe (FERREIRA, 2001).

Dessas origens, há quase cem anos, portanto, um curso recente, a Pedagogia mantém várias características. Entre elas, a existência e obrigatoriedade de estágio.

A LDB 4024/61, a primeira a regulamentar a educação em âmbito nacional, estabelece no artigo 63, a obrigatoriedade do estágio de três anos, para inspetores e, no artigo seguinte, para orientadores educacionais. Àquela época, o Curso formava os especialistas em educação, prerrogativa estabelecida com maior vigor no ano seguinte - 1962, com o Parecer 251, assinado por Valnir Chagas, de caráter premonitório, antecipando duas questões que demarcarão a existência do Curso até o momento: sua inespecificidade e seu lugar quanto a ser ou não o lugar privilegiado para a formação dos professores da infância. Na análise do Parecer, por Saviani, consta:

O texto tece considerações sobre a indefinição do Curso, refere-se à controvérsia relativa à sua manutenção ou extinção, e lembra que a tendência que se esboça no horizonte é a de formação de professores primários em nível superior e a formação dos especialistas em educação em nível de pósgraduação, hipótese que levaria à extinção do curso de pedagogia. (SAVIANI, p. 42, 2007)

O Parecer, ainda, reforçava a necessidade de Prática de Ensino ou Estágio, na esteira do modelo inicial do Curso, denominado $3+1$, bacharelado mais didática. Doravante, o egresso do Curso assume uma característica específica: “[...] a partir de 1962 o pedagogo era identificado como um profissional que personifica a redução da educação à sua dimensão técnica - o técnico de educação-, o currículo previsto para formá-lo era de cunho predominantemente generalista" (SILVA, 2003, p. 53). Esta historicidade foi estabelecendo ao curso de pedagogia um lugar de desvalorização no contexto do ensino superior.

A pedagogia, com a pseudoidentidade inicial, passo a passo foi ocupando lugar periférico no contexto das licenciaturas, sendo essas percebidas como cursos de segunda categoria quando comparadas aos demais cursos 
superiores. Até os professores mais bem preparados da universidade não se dedicavam ao curso de pedagogia. (BRZEZINSKI, 2012, p.221)

Quando, em 1968, durante o Estado Civil e Militar, acontece a Lei da Reforma Universitária, n. 5.540, estabelece-se que o curso de Pedagogia formaria os especialistas em Educação, supervisores, orientadores, administradores e inspetores. Era o tecnicismo evidente na educação naquele período histórico aplicado à Pedagogia. Ano seguinte, pelo Parecer CFE $n^{\circ} 252 / 69$, foi estabelecido o currículo mínimo do Curso e incluída a formação para o trabalho com disciplinas pedagógicas nos cursos Normais, que, associada à formação de especialistas, pareceu ser o rumo idealizado para o Curso.

Apesar das alterações produzidas nos anos seguintes, a efetiva e grande mudança no Curso, assim como nas demais licenciaturas, se evidenciará em 1996, com a publicação da terceira Lei de Diretrizes e Bases da Educação no Brasil, a 9394/96, acabando com as especializações e criando, em acordo com o Parecer de 1961, um curso generalista para formação dos professores da infância. Para tanto, o estágio assume um lugar central. No Título VI "Dos profissionais da educação", artigo 61, que trata dos profissionais para a Educação Básica, parágrafo único, juntamente com a formação teórica sólida, prevista no inciso I, deverá haver "II - a associação entre teorias e práticas, mediante estágios supervisionados e capacitação em serviço" (LDB 9394/96, artigo 61, parágrafo único, inciso II).

Portanto, o estágio se configurou e se mantém como o lugar da prática, após a teoria. Esse modelo é o mesmo da origem do Curso no país, em 1939, separando também a Pedagogia, a Didática e a Metodologia, quando

[...] outro aspecto fundamental para discutir-se a ciência da educação está em considerar que Pedagogia, metodologia e didática são diferentes. [...] Pedagogia é a ciência; metodologia é uma escolha cotidiana feita por quem pensa um ato pedagógico; e didática é a ação pedagógica em si, seu modus operandi e as concepções que o subsidiam. Isto posto, percebe-se que didática e metodologia são integrantes da Pedagogia, e esta é responsável por pensar e propor didáticas e metodologias em acordo com as teorias e entendimentos da educação. (FERREIRA, 2010, p. 235)

Assim, fissurada a relação entre Pedagogia, Didática e Metodologia, também os estágios se fissuram: são tempos e espaços de prática, quando se sabe não há prática se não entendida como evidência da teoria, sem fissuras, sem valorização senão integrada à outra. À integração indissociável entre prática e teoria denomina-se práxis. Por práxis, como se explicitará melhor a seguir, entende-se o trabalho pedagógico, no qual prática e teoria se associam ao ponto de não se fazerem separadas, mas imbricadas, sem que se saiba dissociá-las. A prática é a teoria em 
evidência e a teoria faz acontecer a prática. Todavia, diferentemente dessa compreensão, como se indicará na seção seguinte, os estágios são descritos a partir da concepção que separa teoria e prática.

\section{Projeto Pedagógico: sentidos e possibilidades}

Entende-se Projeto Pedagógico como a expressão da intencionalidade, a descrição teórica e metodológica do Curso e sua configuração. Por isso, é Projeto Pedagógico, na medida em que o pedagógico inclui a dimensão política. Nele, está descrito o trabalho pedagógico a ser desenvolvido. Por trabalho pedagógico, entende-se

[...]um trabalho com características pedagógicas e isso o difere dos demais trabalhos. O pedagógico é sempre político, por implicar escolhas e ações humanas, dentro dos contextos sociais onde se produz. Nesse sentido, exige do sujeito que se movimente entre o que lhe é demandado pelo contexto capitalista e o que acredita como trabalhador. Do mesmo modo, pedagógico é a soma de todas as características que, amalgamadas, contribuem para que se produza conhecimento, desde a infraestrutura escolar até o olhar dos professores em relação aos estudantes, das cores que decoram o ambiente ao modo como se organiza esse ambiente, passando por todos os aspectos culturais e sociais que possibilitam haver uma relação entre sujeitos que visam a conhecer. Trabalho pedagógico, assim, é, como todo trabalho, um modo de o sujeito estar no social como sujeito, mas, complexo e permeado por contradições, um modo de o sujeito contribuir para a reprodução das características desse social. (FERREIRA, 2008; FERREIRA, 2017, p. 175)

Sendo o trabalho pedagógico o trabalho dos professores, o estágio é o tempo e o espaço dos acadêmicos, futuros profissionais, para vivenciá-lo ainda no processo de constituição profissional. A expectativa, ao produzir análise documental dos projetos pedagógicos dos cursos de Pedagogia, das universidades públicas federais gaúchas, era encontrar essa relação melhor explicitada.

Ao analisar os Projetos Pedagógicos dos cursos de Pedagogia observou-se que estão em consonância com as orientações das Diretrizes para a Formação dos Professores (Resolução $\mathrm{CNE} / \mathrm{CP} \mathrm{n}^{\circ} 2$, de $1^{\circ}$ de julho de 2015), em especial, no que tange aos princípios da Formação de Profissionais do Magistério da Educação Básica. No caso deste estudo específico sobre os estágios, observou, em todos os projetos, um destaque para a afirmação relativa à imprescindível articulação entre a teoria e a prática no processo de formação docente e o reconhecimento das instituições de educação básica como espaços necessários à formação dos profissionais do magistério (Resolução $\mathrm{CNE} / \mathrm{CP} \mathrm{n}^{\circ} 2$, artigo $1^{\circ}$, incisos $\mathrm{V}$ e VI, do parágrafo 
$\left.5^{\circ}\right)$. Dois destes projetos apresentam como data das últimas modificações o ano de 2018 , data limite para que fossem realizadas as alterações necessárias, exigidas por aquela Resolução.

Sobre a concepção de estágio nos Projetos Pedagógicos, observou-se que, em nenhum dos projetos, descreve-se diretamente o que seja um estágio. No entanto em todos os projetos há referência à importância das vivências na prática relacionadas às questões teóricas estudadas na academia. Vejamos.

A UFPEL refere-se a algumas disciplinas de "dimensão prática", que objetivam abordar "as discussões realizadas em cada uma delas de um contexto mais situado social e politicamente, além de buscar contribuir para superar uma concepção simplista da prática como sendo um "fazer pragmático" (PP, UFPEL, p.7, 2012). Quanto à FURG, no PP está ressaltado que "todas as disciplinas e atividades terão caráter teórico-prático, como forma de articular a formação do Pedagogo com o seu campo de atuação desde o primeiro ano do curso" (PP, FURG, p. 15, 2016), trabalhando "teoria e prática de forma indissociada" (PP, FURG, p. 15, 2016). Em relação à UNIPAMPA, o PP enfatiza que a função primordial dos estágios é "realizar a articulação efetiva e relevante entre a teoria e a prática, como aspectos básicos e fundamentais da docência" (PP, UNIPAMPA, p.47, 2015). Aponta o estágio como um "momento de análise crítica dos estudos teóricos, se constituindo como parte do processo de aprendizagem e reflexão científica, a partir do exercício da profissão docente” (PP, UNIPAMPA, p.47, 2015). A UFSM considera "a articulação entre os saberes disciplinares e os saberes da prática educativa, entre os saberes da Universidade e os saberes da Escola como focos importantes do trabalho a ser desencadeado na formação inicial” (PP, UFSM, p.3, 2019). Já, na UFRGS, ao longo da formação dos pedagogos, o curso contempla pelo menos 400 horas de práticas pedagógicas nos níveis de Educação Infantil e Anos Iniciais do Ensino Fundamental e Educação de Jovens e Adultos, além da "realização de um estágio de 100 horas destinado ao exercício da prática profissional do pedagogo em diferentes áreas de atuação que não implicam regência de classe" (PP, UFRGS, p.12, 2016). Cada uma das IES apresenta a prática como eixo estruturante do currículo, coadunando-se à Resolução CNE/CP nº 2, de $1^{\circ}$ de julho de 2015.

Quanto aos estágios, ainda prevalece a ênfase dos mesmos na Educação Infantil e nos Anos Iniciais e em alguns cursos os(as) acadêmicos(as) podem optar pelo estágio na Educação de Jovens e Adultos. Na UFPEL, há a possibilidade de estágio obrigatório em gestão com 150 horas. Na UFRGS, há carga horária de 100 horas, destinadas "ao exercício da prática profissional do pedagogo em diferentes áreas de atuação que não implicam em regência de 
classe, como: gestão educacional, educação especial e educação social” (PP, UFRGS, p.23, 2018).

Em suma, a realização dos estágios na Educação Infantil e nos Anos Iniciais está intrinsecamente ligada às Diretrizes Curriculares Nacionais de 2006. Como se pode observar, a possibilidade de os pedagogos trabalharem em outros espaços não foi priorizada nessa política educacional, apenas possibilitada. Por essa razão, apesar de alguns esforços, o foco do curso de Pedagogia é, prioritariamente, a formação de professores. Nesse viés, o estágio se apresenta como ensaio para o trabalho dos egressos, porém, nem sempre vivenciado intensamente durante os estudos, dadas as limitações de tempo e à especificidade nos projetos pedagógicos.

\section{Outros sentidos produzidos: experiências e necessidades no estágio}

O objetivo da etapa de interlocução com os egressos foi perceber se os sentidos produzidos sobre os Estágios Supervisionados estavam em consonância com os sentidos evidenciados nos PPs e nos Currículos dos cursos. Assim passa-se a organizar esta análise, a partir dos dados produzidos em quatro pontos: a) experiências de estágio, b) necessidades do estágio, c) relação da teoria, da prática e práxis no curso de Pedagogia, d) desafios da docência.

Onze pedagogos egressos da UFSM, entre os anos de 2013 e 2020, relataram sobre suas experiências, sentidos de estágio e sobre a relação teoria e prática. Entre os pedagogos que responderam ao questionário, $55 \%$ deles terminaram o Curso em seu tempo previsto de quatro anos, conforme previsto no Projeto Pedagógico vigente no período de estudos. Os egressos relataram suas experiências de estágio, e, de modo geral, os discursos demonstraram a necessidade de "colocar os acadêmicos em mais tempo de prática dentro das escolas em diferentes contextos. Ensinar os estudantes a fazer propostas diferentes, não só na teoria” (E1).

Percebeu-se que os discursos dos egressos divergiram bastante em relação às experiências, relataram que não são todas as disciplinas que unem teoria e prática e que esta união fica a cargo de algumas disciplinas, mas é no estágio que isso se torna real: "Mas isso ficou mais visível durante as minhas propostas nos anos iniciais durante o estágio supervisionado" (E1). Estágio este que está previsto para o $8^{\circ}$ semestre, ou seja, o último ano de Curso, fazendo com que os futuros pedagogos não tenham tempo para planejamento, maturação, análise e sistematização de suas práticas, devido ao fato de neste ano, no PP haver previsão de dois estágios e da escrita de um Trabalho de Conclusão de Curso - TCC.

Em decorrência desta situação, relataram que, nos últimos anos, suas turmas solicitaram mudança no Curso. Sete pedagogos relataram que suas turmas indicaram adicionar mais 
estágios, mais práticas ao Curso, inseridas em cada disciplina escolar. E um dos entrevistados afirmou que o melhor momento no Curso, em relação às práticas desenvolvidas, foi no chamado "bloco do $7^{\circ}$ semestre". Neste período, tinham "aula/orientação no turno inverso às práticas, e que isso fazia toda a diferença no processo de construção da nossa prática” (E5).

No Projeto Pedagógico do Curso de Pedagogia da Universidade Federal de Santa Maria, desenvolvido em 2007, que orientou o Curso realizado pela maioria dos entrevistados, era contemplado, no "Perfil desejado do formando" e, nele, percebe-se a relação teoria e prática: "Este profissional, que tem como base de formação a docência, precisará desenvolver saberes docentes que incluam conhecimentos teóricos e práticos no campo da educação e dos conhecimentos que irão mediar sua atividade nas instituições escolares e não-escolares" (PP, UFSM, 2007).

Ao questioná-los sobre como percebiam esta relação, seis afirmaram que não percebiam a relação entre a teoria e a prática. Dentre estas: “Às vezes, algumas ideias não condizem com a realidade encontrada na escola" (E11). Já, outros cinco afirmaram perceber a relação em aula, durante o Curso: "Quando se pensava um trabalho para realizar com as crianças levava em conta a faixa etária para compreensão do desenvolvimento cognitivo de cada" (E10). Evidenciou-se nesta fala a importância da relação teoria e prática, e que, quando vista no curso, é valorizada como um momento para "tirar dúvidas, articular ideias, compartilhar angústias e conquistas com a professora e as colegas. As leituras que fizemos também parecerem ser mais significativas pois conseguíamos relacionar com a prática" (E5).

A fim de maiores explicações sobre esta falta de retorno das atividades práticas realizadas, perguntou-se aos egressos se, durante o Curso de Pedagogia, estudaram, ouviram, abordaram sobre práxis. Classificou-se as respostas, especialmente as concepções de práxis, de acordo com as áreas de concentração a) reflexão e transformação (cinco egressos); b) teoria e prática (dois egressos); c) ação pedagógica (dois egressos); e dois afirmaram não ouvir esta palavra na graduação, enquanto um disse que conheceu em contato com um grupo de pesquisa. No PPP do Curso, não aparece o termo práxis, com esta terminologia, mas aparece de forma variada relacionado à prática, à ação e à transformação o que dá indícios para entender-se sobre a pluralidade do termo em relação às respostas dos egressos.

Entende-se que práxis acontece em meio às relações entre os seres humanos, estabelecidas na medida em elaboram as condições, pelo trabalho, para sobreviver. Refere-se, então, à necessária elaboração de condições materiais para existir e se autoproduzir humano: “o homem se faz e se transforma ao transformar o mundo" (IMBERT, 2003, p. 13). É uma das 
razões pelas quais práxis e prática não são sinônimos, mas se complementam. Aquela é transformadora; esta, por não denotar caráter revolucionário, que possibilite ao sujeito comprometer-se com o seu mundo, pode se restringir somente ao tempo presente, sendo assim instantânea e isolada de um projeto social.

E falar da educação como práxis é afirmar que ela não pode ser reduzida a uma técnica, aqui entendida como mera aplicação de conhecimentos préelaborados, como se estivéssemos a demonstrar um teorema. E assim como a educação, a política e a administração, em geral e, de modo especial, no que se aplica à educação. (CORDOVA, 1994, p. 42)

A práxis demanda inter-relação, circulação da linguagem, projeto coletivo (o PP, por exemplo). Não há de fato concordância de que práxis seja apenas um sentido, mas concorda-se que é necessário um tempo, seja curto ou longo, para o amadurecimento da prática do professorado, e que, assim como afirma no Projeto de um dos Curso, reconhecendo os limites da ação.

Pretendemos chegar à formação de um profissional capacitado para agir nas diversas realidades educacionais no decorrer da sua atividade docente e contribuir, mesmo reconhecendo os limites de ação da educação escolar, para a transformação da sociedade, resgatando-se o aspecto social como fonte de reflexão profissional, geradora de saberes. (PP, UFSM, 2007)

Além deste tempo necessário, nas respostas ao questionário, sobressaiu-se a necessidade de mais práticas durante a graduação, e ao observar o Projeto do Curso o qual afirma que as disciplinas são organizadas por uma matriz curricular que relaciona as disciplinas com as Práticas Educativas, disciplina presente em sete semestres, conhecida como "PED” abordando, a cada semestre, uma temática: 1) Educação, Tempos e Espaços; 2) Conhecimento e Educação, 3) Contextos e Organização Escolar; 4) Saberes e Fazeres na Educação Infantil; 5) Saberes e Fazeres no Ensino Fundamental; 6) Saberes e Fazeres da Educação nas suas Diferentes Modalidades; 7) Saberes e Fazeres na Educação Básica;

Apreendeu-se que, em sua descrição, estas disciplinas contemplam a relação teoria e prática, mas de fato, em sua efetivação, conforme os relatos dos egressos, quando se perguntou em qual semestre iniciaram as práticas, ninguém recordou ao certo a primeira inserção na escola, e acabaram confundindo inserção com observação e entrevistas realizadas nas escolas. Entre os interlocutores, três realizaram inserção no $4^{\circ}$ semestre da graduação, e três afirmaram ser no $3^{\circ}$ semestre, enquanto dois afirmaram ser no quinto semestre e um afirmou ter sido no segundo semestre. A diferenciação entre as respostas confirma o esquecimento antes referido. 
Ao serem questionadas sobre outras práticas realizadas além das constantes na matriz curricular, evidenciaram a preocupação em realizar a maior quantidade possível de práticas visando à maior preparação/qualificação/segurança no futuro trabalho profissional, ou seja, indicando que incluíram em seus projetos de vida profissional a primazia da prática como fonte e modo de se constituírem professores, sem relacioná-la à teoria ou evidenciar o entendimento de práxis.

Nesse contexto, os interlocutores, em seus discursos, localizaram os estágios. Os sentidos lidos em suas respostas quanto ao estágio foram assim sistematizados em gráfico:

Gráfico 1 - Estágio extracurricular.

\section{Experiência extracurricular}

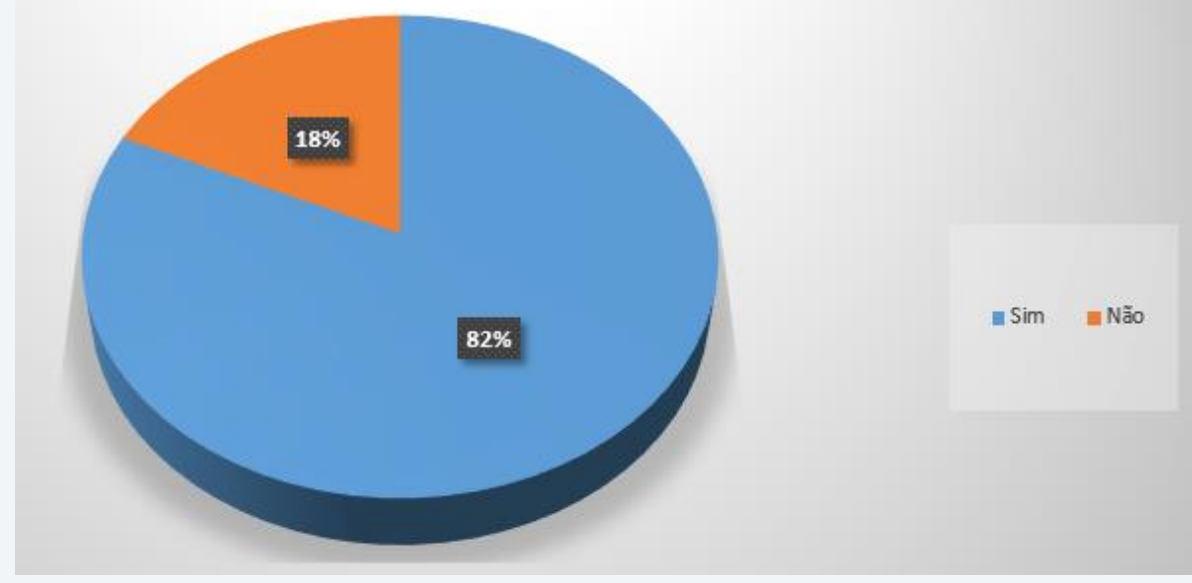

Fonte: Elaborada pelas autoras, com base nos questionários analisados, 2020.

Mais uma vez percebeu-se, nos discursos, a evidência da necessidade das práticas, sejam elas obrigatórias ou não. Sete egressos afirmaram que foram fundamentais para o estágio, as disciplinas mais práticas do Curso, enquanto quatro afirmaram serem mais necessárias as teóricas, como, por exemplo, Psicologia da educação. E, quando questionados sobre o maior desafio do estágio, destacaram novamente a falta de práticas e dificuldades em organizar os planejamentos, encontrar metodologias para trabalhar, e, do mesmo modo, a dificuldade em executar os planejamentos.

Instigados a pensar sobre a conclusão do Curso e sobre estar "pronta" para trabalhar como pedagoga na escola, três afirmaram que, ao final da graduação, se sentiram preparados. Um dos entrevistados afirmou que se sentiu preparado devido ao Curso Normal realizara anteriormente ao Curso de Pedagogia. Sete afirmaram não estarem preparadas para a docência, 
encararem a profissão como "um desafio diário, imprevisível, em que deve saber lidar com atividades e atitudes diversas" (E3). Ainda, outra pedagoga afirmou que a graduação deu o suporte e que cabe ao profissional atualizar-se:

A questão é que nunca estarei pronta, estou e busco estar em constante evolução. Cada ano haverá uma turma diferente com crianças que possuem demandas específicas. Eu, como profissional, tenho em minhas mãos a base que o curso me deu, e o compromisso de buscar me aperfeiçoar para desenvolver um trabalho significativo com as crianças. (E5)

Outra pedagoga, em sua resposta, separou Educação Infantil e Anos Iniciais do Ensino Fundamental, afirmando estar preparada para trabalhar na Educação Infantil, pois "não abrange tanto conteúdo" (E8), enquanto para os anos iniciais ela não se sentia preparada, teria “dificuldade em algumas disciplinas e não gostaria de passar para meus alunos. E o curso não nos prepara para ensinar esses conteúdos" (E8). Entretanto, de acordo com a Resolução CNE/CP 01/2006, os egressos do Curso poderão trabalhar como professores da infância, na Educação Infantil e nos Anos Iniciais. Por essa razão, há 300 horas para o Estágio Supervisionado, na matriz curricular do Curso realizado pelos interlocutores.

Sobre os desafios da docência no estágio, expressos nas entrevistas, identificou-se vários e classificou-se em dois blocos: a) um teórico, referente a mediar as expectativas da estagiária e as necessidades dos seus estudantes: "Relacionar as minhas práticas às demandas da turma, pois eram crianças que estavam em vulnerabilidade social. Relacionar a família, escola e comunidade" (E1); "Aprender a ser professora de bebês. Não vimos muito sobre educação de bebês durante o curso, e são sujeitos complexos que, ao contrário do que se pensa, o trabalho com bebês não tem a ver com maternidade e sim com horas de estudo e pesquisa sobre suas particularidades" (E5); “As inúmeras demandas de diferentes perfis" (E7), "Foi desenvolver e articular espaços que instigassem as crianças” (E9); “[...] lidar com crianças em diferentes fases de aprendizagem na mesma turma" (E11).

Os outros desafios citados estavam ligados b) à questão técnica relacionada à escolha das metodologias e organização de planejamentos: "Sobre a questão de escolher as melhores metodologias e estratégias de ensino para realmente auxiliar as crianças nos seus processos de construção de conhecimento" (E2); "Todos os possíveis, pois tinha que pesquisar muitos jogos e metodologias que a graduação em si não deu conta, além dos conteúdos a serem trabalhados". (E3), “Construir os planejamentos” (E4); “O maior desafio não foi relacionado à turma, à professora regente ou aos conteúdos, mas a uma organização mais "didática" (escrita no quadro, organização e confecção de materiais, trabalhos manuais) (E6); "Saber como ensina os 
conteúdos para as crianças usando as teorias aprendidas no curso"(E8); "A rotina fixa da escola" (E10).

Os diferentes desafios citados pelos egressos coincidem com o relato de Oliveira; Rocha e Broch (2020) sobre suas experiências de estágio no curso de licenciatura em Matemática: “o estágio permite que o acadêmico consiga aplicar os aportes teóricos elaborados na licenciatura em situações práticas vivenciadas na escola" (p.64). Ainda de acordo com os autores "a experiência do estágio apresenta-se como um segundo momento no ciclo formativo, em que os conceitos aprendidos perdem a inércia e passam para um fazer de forma ágil” (ibidem). Fica evidente que apesar de serem estudados os mais variados aspectos teóricos relacionados à educação e ao cotidiano escolar, sempre haverá diversificadas experiências para serem vivenciadas, sendo que a maioria delas serão descobertas na convivência com os estudantes, no dia-a-dia escolar.

\section{Considerações finais}

O presente estudo buscou compreender o lugar e as experiências de Estágio nos cursos de Pedagogia do RS. Percebeu-se que a organização dos estágios não está clara nos PPs. Entende-se que este momento, assim como a relação teoria e prática nos cursos é fundamental. É um estudo que não se encerra com esta sistematização, ora apresentada sob a forma de artigo: "Ele deve constituir, dialeticamente, um movimento...um caminho aberto a críticas e as outras pesquisas que pretendam acompanhar a nova trajetória na busca progressiva da identidade do pedagogo e da pedagogia e na luta pela valorização social e econômica dos profissionais da educação. (BRZEZINSKI, 2012, p.16).

Com o intuito de alinhavar o estudo até este momento, cabe tecer algumas considerações:

a) há um direcionamento nos projetos pedagógicos dos Cursos de Pedagogia, porém não existe um sentido de estágio supervisionado explicitado nos mesmos. A falta de sentido acaba por refletir a mesma situação nos discursos dos egressos do Curso de Pedagogia, pois, em seus relatos, destaca-se a necessidade de haver mais tempo de prática dentro das escolas. Outros aspectos que justificam essa consideração: I) o fato de que são poucas disciplinas que unem teoria com a prática; II) a complexidade dos relatos em que apenas três entrevistados sentemse preparados para a docência, ao ponto de um deles agregar sua condição de sentir em 
condições de trabalhar, devido ao Curso Normal que realizou anteriormente ao Curso de Pedagogia;

b) a falta de um sentido assumido pelos interlocutores da pesquisa parece afetar o trabalho pedagógico que realizam. Isto porque se não há um sentido claro, também não há o entendimento de que teoria e prática devem sempre estar imbricadas, associadas ao ponto de não se fazerem separadas. Como já dito anteriormente, o trabalho pedagógico considera que a prática é a teoria em evidência e a teoria faz acontecer a prática. Como os estágios são descritos a partir da compreensão que se separa teoria e prática, entende-se que os egressos sempre terão dificuldades de perceber a importância de constituir um sentido para o seu trabalho.

Outrossim, o estágio, mesmo sendo uma exigência legal, necessita ser repensado dentro do projeto pedagógico do curso de Pedagogia e inserido na “[...] luta pela melhoria dos cursos de formação de professores, pela valorização do magistério e por uma escola de ensino fundamental e médio mais democrática e eficiente" (LIMA, 2002, p. 252). Ou seja, necessita de redimensionamento, passando a ser um tempo e um espaço sim de inserção na profissão, mas eivado de sentidos, de modo político, práxico, portanto.

\section{REFERÊNCIAS}

BRASIL. Decreto-Lei n⿳ 1.190, de 4 de abril de 1939. Dá organização à Faculdade Nacional de Filosofia. Rio de Janeiro, 4 de abril de 1939.

BRASIL. Lei 4.024. De 20 de Dezembro de 1961. Fixa as Diretrizes e Bases da Educação Nacional. Brasília, DF, 20 dez. 1961

BRASIL. Parecer n. 251/62. Currículo mínimo e duração para o curso de graduação em Pedagogia. Brasília, DF, 1962.

BRASIL. Lei no 5.540, de 28 de Novembro de 1968. Fixa normas de organização e funcionamento do ensino superior e sua articulação com a escola média, e dá outras providências. Brasília, 28 de novembro de 1968.

BRASIL. Conselho Federal de Educação. Parecer n. 252/1969. Estudos pedagógicos superiores. Mínimos de conteúdos e duração para o curso de graduação em pedagogia. Brasília, DF, 1969.

BRASIL. Lei 9.394, de 20 de dezembro de 1996. Estabelece as diretrizes e bases da educação nacional. Brasília, DF, 23 dez. 1996.

BRASIL. Ministério da Educação. Resolução CNE/CP Nº 1/2006 Diretrizes Curriculares para o Curso de Pedagogia. Brasília, DF, 2006. 


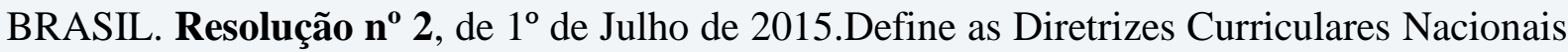
para a formação inicial em nível superior e para a formação continuada. Brasília, DF, 2 de julho de 2015.

BRZEZINSKI, Iria. Pedagogia, pedagogos e formação de professores: busca e movimento. 9 ed. Campinas, São Paulo: Papirus, 2012.

CORDOVA, Rogério. A. "Imaginário social e educação: criação e autonomia". Em Aberto. Brasília, ano 14, n.61, jan./mar. 1994. p. 24-44.

FERREIRA, Liliana Soares. Educação \& história. Ijuí: Editora UNIJUI, 2001.

FERREIRA, Liliana Soares. “Gestão do pedagógico: de qual pedagógico se fala?” Currículo sem Fronteiras, v. 8, n. 2, jul/dez 2008, pp. 176-189.

FERREIRA, Liliana Soares. Pedagogia como ciência da educação: retomando uma discussão necessária. Revista Brasileira de Estudos Pedagógicos, v. 91, n. 227 (2010), p.233 - 251

FERREIRA, Liliana Soares. "Pedagogia nos cursos de Pedagogia? Da ausência e dos impactos no trabalho pedagógico”. In: Revista Espaço do Currículo, João Pessoa, vol. 10, n. 02, 2017, pp. 174-190.

IMBERT, Francis. Para uma práxis pedagógica. Brasília: Plano Editora, 2003

LIMA, M. S. L. (2002) "Práticas de estágio supervisionado em formação continuada" In: ROSA, D. E. G.; SOUZA, V. C. S.; FELDMAN, D. et alii. Didática e práticas de ensino: interfaces com diferentes saberes e lugares formativos. Rio de Janeiro: DP\& A.

OLIVEIRA, Everaldo Romoã de; ROCHA, Aristeu Castilhos da; BROCH, Siomara Cristina. Matemática e História: investigação e vivências no estágio curricular supervisionado. In: BROCH, Siomara Cristina, SOUZA, Rosangela Segala. Estágio Curricular: contribuições para a formação docente (ORGs). Curitiba: CRV, 2020.

PROJETO PEDAGÓGICO. Centro de Educação - Projeto Político-Pedagógico do Curso de Pedagogia Licenciatura Plena. Santa Maria, 2007.

PROJETO PEDAGÓGICO. Faculdade de Educação. Projeto Pedagógico do Curso de Pedagogia Licenciatura. Pelotas, maio de 2012

PROJETO PEDAGÓGICO. Instituto de Educação - Projeto Pedagógico do Curso de graduação Pedagogia - Licenciatura. Rio Grande, 2016

PROJETO PEDAGÓGICO. Campus Jaguarão. Projeto Político-Pedagógico do Curso de Graduação em Pedagogia - Licenciatura. Jaguarão, 2015.

PROJETO PEDAGÓGICO. Faculdade de Educação. Projeto Pedagógico de Curso Licenciatura em Pedagogia. Porto Alegre, 2018. 
PROJETO PEDAGÓGICO. Centro de Educação - Projeto Político-Pedagógico do Curso de Pedagogia Licenciatura Plena. Santa Maria, 2019.

SAVIANI, Dermeval. A Pedagogia no Brasil: história e teoria. São Paulo: Autores Associados, 2008.

SAVIANI, D. O lugar estratégico do mestrado no conjunto da pós-graduação e da pedagogia: problemas e perspectivas. In: FERREIRA, N. S. C. (Org.). A pesquisa na pós-graduação em educação: reflexões, avanços e desafios/produção e apropriação do conhecimento. Curitiba: UTP, 2007. p. 33-54. (Cadernos de Pesquisa do Programa de Mestrado em Educação, v. 2, n. $3)$.

SILVA, Carmem Silva Bissolli da. Curso de pedagogia no Brasil: história e identidade. 3. ed. Campinas, SP: Autores Associados, 2006.

\section{SOBRE AS AUTORAS:}

\section{Liliana Soares Ferreira}

Doutora em educação. Professora do Programa de Pós-graduação em Educação da Universidade Federal de Santa Maria (UFSM). Líder do Kairós - Grupo de Estudos e Pesquisas sobre Trabalho, Educação e Políticas Públicas. Bolsista produtividade CNPQ, área de educação. E-mail: anaililferreira@yahoo.com.br

(iD) http://orcid.org/0000-0003-4847-9148

\section{Luiza da Silva Braido}

Mestranda em educação, pela Universidade Federal de Santa Maria (UFSM). Bolsista de Demanda Social - Capes. Integrante do Kairós - Grupo de Estudos e Pesquisas sobre Trabalho, Educação e Políticas Públicas. E-mail: luizasbraido@gmail.com

(iD http://orcid.org/0000-0001-5685-6260

\section{Mariglei Severo Maraschin}

Doutora em Educação pela Universidade Federal de Santa Maria (UFSM). Professora Programa de Pós-graduação em Educação Profissional do Colégio Técnico Industrial da Universidade Federal de Santa Maria. Líder do grupo TransformAção - Grupo de Estudos e Pesquisas em Políticas e Trabalho Pedagógico na Educação Profissional, e integrante do Kairós - Grupo de Estudos e Pesquisas sobre Trabalho, Educação e Políticas Públicas. E-mail: marigleism@ hotmail.com

iD http://orcid.org/0000-0002-9705-1896

\section{Dulcineia Libraga Papalia de Toni}

Doutoranda em Educação pela Universidade Federal de Santa Maria (UFSM). Coordenadora pedagógica da Educação Infantil na Escola Medianeira - Brasil. Integrante do Kairós - Grupo de Estudos e Pesquisas sobre Trabalho, Educação e Políticas Públicas. E-mail: dulcidetoni@yahoo.com.br

(iD http://orcid.org/0000-0002-0511-4811 